\title{
Peran Stakeholder Dalam Upaya Reintegrasi Sosial Kasus Kekerasan Pada Anak di Kota Semarang
}

\author{
Masyhurah"1, Tri Yuningsih², Ida Hayu DM³ \\ ${ }^{123}$ Departemen Administrasi Publik, Fakultas Ilmu Sosial dan Ilmu Politik Universitas \\ Diponegoro, Jl. Imam Bardjo SH No. 3-5 Semarang
}

\section{ARTICLE IN F O}

\section{Article history:}

Received 06/02/2021

Received in revised form 28/03/2021

Accepted 30/03/2021

\begin{abstract}
Children are vulnerable to becoming victims of violence in both developing and developed countries. Various regulations were made to end violence against children. Semarang City Government seeks to protect children from violence through Regional Regulation Number 05 of 2016 and forming a child protection organization through Semarang Mayor Regulation Number 05 of 2018. Implementation of social reintegration for child victims of violence in Semarang City involves many stakeholders. This study aims to analyze the role of stakeholders and determine the inhibiting factors for the role of stakeholders. The method used is descriptive qualitative. The results of the research show that The Women Empowerment and Child Protection Regional Office play a role as a policy creator, implementor, coordinator, facilitator, and accelerator. PPT SERUNI, PPT Kecamatan, and Pos JPPA play a role as implementers, coordinators, facilitators, and accelerators. Regional Offices, Rumah Duta Revolusi Mental, hospitals, academic, and Bhabinkamtibmas play a role as facilitators and accelerators of child protection and social reintegration. The inhibiting factors for social reintegration in cases of violence against children include the community culture that discriminates against victims, limited reintegration budgets, trauma in victims that causes victims to be reluctant to return to school or return to social institutions, and regulations governing social reintegration are still weak. The recommendation conveyed is that the Office of Women's Empowerment and Child Protection conducts outreach on child protection services and educates schools and social institutions about preventing violence, the importance of recovery and reintegration for victims of violence, the Office of Women's Empowerment and Child Protection should increase the budget for child protection and collaborate with other stakeholders to finance the social reintegration of child victims of violence, the victim should conduct regular counseling with the PPT SERUNI or RDRM's psychologist, and the government should passing new regulations that explain in detail social reintegration according to the needs of victims.
\end{abstract}

Keywords : roles, stakeholders, social reintegration, child protection 


\begin{abstract}
Abstrak
Anak rentan menjadi korban kekerasan baik di negara berkembang maupun negara maju. Berbagai regulasi dibuat untuk menyudahi tindak kekerasan terhadap anak. Pemerintah Kota Semarang berupaya melindungi anak dari kekerasan melalui Peraturan Daerah Nomor 05 Tahun 2016 dan membentuk lembaga pengelenggara perlindungan anak melalui Peraturan Walikota Semarang Nomor 05 Tahun 2018. Penyelenggaraan reintegrasi sosial bagi anak korban kekerasan di Kota Semarang melibatkan banyak stakeholder. Penelitian ini menganalisa peran stakeholder dan mengetahui faktor penghambat peran stakeholder. Metode yang digunakan adalah deskriptif kualitatif. Hasil penelitian menunjukkan bahwa Dinas Pemberdayaan Perempuan dan Perlindungan Anak berperan sebagai policy creator, implementor, koordinator, fasilitator, dan akselerator. PPT SERUNI, PPT Kecamatan, dan Pos JPPA berperan sebagai implementor, koordinator, fasilitator, dan akselerator. OPD, Rumah Duta Revolusi Mental, rumah sakit, akademisi, dan Bhabinkamtibmas berperan sebagai fasilitator dan akselerator perlindungan anak dan reintegrasi sosial. Faktor penghambat reintegrasi sosial kasus kekerasan pada anak antara lain kultur masyarakat yang mendiskriminasi korban, anggaran reintegrasi yang terbatas, trauma dalam diri korban yang menyebabkan korban enggan kembali bersekolah atau kembali ke panti sosial serta regulasi yang mengatur reintegrasi sosial masih lemah. Rekomendasi yang diberikan adalah Dinas Pemberdayaan Perempuan dan Perlindungan Anak perlu melakukan sosialisasi mengenai layanan perlindungan anak serta mengedukasi sekolah dan panti sosial tentang pencegahan kekerasan, pentingnya pemulihan dan reintegrasi bagi korban kekerasan, DP3A juga perlu menambah anggaran perlindungan anak serta bekerjasama dengan stakeholder lain untuk membiayai reintegrasi sosial anak korban kekerasan, korban kekerasan perlu melakukan konseling secara berkala dengan psikolog PPT SERUNI atau RDRM, serta perlunya regulasi baru yang menjelaskan secara detail mengenai reintegrasi sosial sesuai kebutuhan korban.
\end{abstract}

Kata kunci: peran, stakeholder, reintegrasi sosial, perlindungan anak

*)Penulis Korespondensi

E-mail : masyhurah@student.undip.ac.id

\section{PENDAHULUAN}

Di negara berkembang dan negara maju, perempuan dan anakanak rentan menjadi korban kekerasan. Oleh karena itu, banyak negara dan LSM memberikan perhatian khusus untuk melindungi perempuan dan anak dari kekerasan. Berbagai regulasi telah dirumuskan untuk menghentikan kekerasan terhadap perempuan dan anak. Negara bahkan Perserikatan Bangsa-Bangsa dan organisasi dunia lainnya sudah mulai menerapkan kebijakan yang dapat mengurangi angka kekerasan. PBB bahkan secara spesifik menargetkan untuk mengakhiri kekerasan terhadap perempuan dan anak pada 2030 dalam Tujuan Pembangunan Berkelanjutan (SDGs).
“Undang-Undang Dasar Tahun 1945 telah membahas mengenai perlindungan anak. Pasal 28B ayat (2) UUD 1945 menyatakan bahwa setiap anak berhak atas kelangsungan hidup, tumbuh dan berkembang serta berhak atas perlindungan dari kekerasan dan diskriminasi. Perlindungan anak dijelaskan kembali dalam UndangUndang Nomor 35 Tahun 2014 tentang Perubahan Atas UndangUndang Nomor 23 Tahun 2002 tentang Perlindungan Anak. UndangUndang tersebut mengatur bahwa setiap orang dilarang menempatkan, membiarkan, melakukan, menyuruh melakukan, atau turut serta melakukan kekerasan terhadap anak."

Anak adalah seseorang yang belum berusia 18 tahun. WHO 
mendefinisikan kekerasan anak sebagai segala bentuk perlakuan yang salah baik secara fisik, emosional, seksual, penelantaran, dan eksploitasi yang membahayakan kesehatan anak dan perkembangan anak. Jenis kekerasan yang terjadi pada anak antara lain kekerasan fisik, kekerasan psikis, kekerasan seksual, penelantaran, perlakuan salah dan trafficking. Fenomena kekerasan anak cenderung meningkat setiap tahunnya. Oleh karena itu, perlu ada kebijakankebijakan yang dapat melindungi anak dari tindak kekerasan hingga mengembalikan fungsi sosial anak ke lingkungannya. Perlindungan anak adalah segala upaya untuk menjamin hak-hak anak agar dapat hidup, tumbuh, berkembang, dan berpartisipasi secara optimal sesuai dengan harkat dan martabat kemanusiaan, serta mendapat perlindungan dari kekerasan dan diskriminasi. Perlindungan anak bukan hanya merupakan tanggungjawab orangtua, tetapi juga keluarga, masyarakat, dan pemerintah. Perlindungan anak penting untuk dilakukan mengingat kekerasan yang dialami anak akan berdampak pada kehidupannya di masa depan. Noviana (2015) menyatakan bahwa kekerasan pada anak tidak hanya melanggar moral dan hukum tetapi juga membawa dampak fisik dan psikologis pada anak. Kekerasan pada anak, baik secara fisik, psikis, maupun seksual akan menimbulkan dampak traumatis pada anak. Noviana (2015) menjelaskan bahwa dampak psikologis yang mungkin terjadi dapat berupa stress, depresi, perasaan bersalah dan menyalahkan diri sendiri serta ketakuan dengan lingkungan.

Kota Semarang merupakan kota dengan jumlah kekerasan anak tertinggi di Jawa Tengah. Upaya Pemerintah Kota Semarang dalam mengakhiri kekerasan pada anak tertuang dalam Peraturan Daerah Kota Semarang Nomor 5 Tahun 2016 tentang Perlindungan Perempuan dan Anak dari Tindak Kekerasan. Kemudian dijelaskan kembali dalam Peraturan Walikota Semarang Nomor 5 Tahun 2018 tenatang Lembaga Penyelenggara Perlindungan Perempuan dan Anak dari Tindak Kekerasan di Kota Semarang.

Salah satu kebutuhan anak korban kekerasan adalah reintegrasi sosial. Reintegrasi sosial adalah upaya yang dilakukan untuk megembalikan fungsi sosial anak di lingkungan masyarakat. Reintegrasi sosial mencakup pemenuhan hak-hak dasar bagi anak korban kekerasan seperti hak pendidikan, pengasuhan alternatif, dan perlindungan dari kekerasan. Dalam Peraturan Daerah Kota Semarang Nomor 5 Tahun 2016 menjelaskan bahwa reintegrasi sosial bagi anak korban kekerasan mencakup pemulihan dan pendampingan psikososial, pemulihan kesehatan, penyiapan lingkungan keluarga dan sekolah.

Pelaksanaan reintegrasi sosial bagi anak korban kekerasan penting untuk dilakukan. Selain berupaya untuk mengembalikan kepercayaan diri anak dan memberikan jaminan pemenuhan hak-hak anak, Reintegrasi sosial juga bertujuan untuk melindungi anak Indonesia dari persoalan sosial lain dan mengembangkan potensi sosialnya sebagai generasi penerus bangsa. Pelaksanaan reintegrasi sosial kasus kekerasan anak di Kota Semarang melibatkan kerjasama dari berbagai stakeholder. Perlindungan anak di Kota Semarang menjadi tanggung jawab Dinas Pemberdayaan Perempuan dan Perlindungan Anak. Dinas Pemberdayaan Perempuan dan Perlindungan Anak kemudian membentuk lembaga penyelenggara perlindungan perempuan dan anak dari tindak kekerasan di Kota 
Semarang yang terdiri dari PPT SERUNI, PPT Kecamatan, Pos JPPA dan Rumah Duta Revolusi Mental. Stakeholder yang terlibat dalam perlindungan anak memiliki perannya masing-masing dan saling bergantung satu sama lain. Stakeholder dinilai berperan baik apabila telah memenuhi tugas dan fungsi sesuai dengan kedudukan atau jabatan yang diberikan. Meskipun begitu, masih terdapat berbagai permasalahan dalam proses reintegrasi anak korban kekerasan di Kota Semarang.

Pelaksanaan reintegrasi sosal di Kota Semarang belum berjalan secara optimal. Wati (2016) menyebutkan bahwa lembaga penanggungjawab perlindungan anak di Kota Semarang, DP3A dinilai belum menginformasikan perlindungan anak kepada masyarakat secara maksimal. Penelitian Krisdyawati (2019) mengungkapkan bahwa masyarakat kurang memahami pentingnya perlindungan anak akibat minimnya informasi yang disampaikan oleh DP3A. Selain terjadi di masyarakat, diskriminasi korban juga terjadi di lingkungan sekolah dan pansti sosial.

PPT SERUNI dan PPT

Kecamatan sebagai lembaga yang menyelenggarakan layanan reintegrasi sosial memiliki fungsi yang sama sehingga rentan mengalami tumpang tindih peran (Putrihartiwi, 2017). Selain itu, Berdasarkan hasil pra survey pada bulan November 2019 dengan Rumah Duta Revolusi Mental diketahui bahwa RDRM sebagai bagian dari kebijakan perlindungan anak Kota Semarang telah berpindah tanggungjawab ke Dinas Pendidikan pada awal tahun 2019. Meskipun begitu, apabila kasus kekerasan maka kasus tersebut dapat dilimpahkan kembali ke Dinas Pemberdayaan Perempuan dan Perlindungan Anak. Pernyataan ini menunjukkan ketidakefektifan fungsi dari dua lembaga perlindungan anak.

Melihat fenomena di atas, dapat disimpulkan bahwa peran stakeholder yang terlibat dalam reintegrasi sosial anak korban kekerasan di Kota Semarang belum optimal, sehingga penelitian ini menjawab pertanyaan sebagai berikut : Pertama, bagaimana peran stakeholder yang terlibat dalam upaya reintegrasi sosial kasus kekerasan pada anak di Kota Semarang; Kedua, faktor-faktor apa yang menghambat peran stakeholders yang terlibat dalam upaya reintegrasi sosial kasus kekerasan pada anak di Kota Semarang.

\section{METODE PENELITIAN}

Penelitian ini menggunakan tipe penelitian deskriptif dengan pendekatan kualitatif. Pendekatan kualitatif dipilih karena permasalahan reintegrasi sosial melibatkan banyak stakeholder dan bersifat dinamis. Kota Semarang dipilih menjadi situs penelitian karena merupaka kota dengan jumlah kasus tertinggi di Jawa Tengah. Data yang digunakan dalam penelitian ini adalah data primer (berdasarkan hasil wawancara dengan narasumber) dan data sekunder (buku-buku pustaka, berita, jurnal, dan regulasi). Penentuan narasumber menggunakan teknik purposive dan teknik snowball. Pengumpulan data dilakukan dengan cara wawancara secara langsung, daring dan/atau telepon, email, dokumentasi dan observasi. Analisis data yang digunakan dalam penelitian ini berasal dari Seiddel (dalam Moleong, 2016). Validitas data menggunakan teknik triangulasi sumber, triangulasi teknik, dan triangulasi waktu (Sugiyono, 2016). Teori yang digunakan dalam penelitian ini merupakan teori peran stakeholder. Hal ini dikarenakan proses 
reintegrasi sosial anak korban kekerasan melibatkan berbagai stakeholder yang saling bekerjasama satu sama lain. Menurut Soekanto dalam Mahfud (2015), peran adalah pelaksanaan kewajiban dan hak sesuai dengan kedudukannya. Peran merupakan konsekuensi yang timbul dari adanya kedudukan atau kewenangan. Stakeholder dinilai telah berperan dengan baik apabila telah memenuhi tugas dan kewajiban sesuai dengan kedudukannya. Sementara stakeholder menurut Freeman dalam Putri, DF (2018) adalah kelompok atau individu yang dipengaruh atau mempengaruhi suatu pencapaian tujuan organisasi. Brysson dalam Putri, DF (2018) mendefinisikan stakeholder sebagai individu, kelompok, atau organisasi yang memiliki perhatian terhadap sumberdaya atau hasil (output) organisasi atau dipengaruhi oleh hasil tersebut. Dengan demikian, dapat disimpulkan bahwa peran stakeholder merupakan tugas dan jabatan pemangku kepentingan sesuai dengan jabatan yang diberikan. Sebuah kebijakan akan berhasil apabila setiap stakeholder telah memenuhi tugas dan kewajibannya.

Teori stakeholder yang digunakan dalam penelitian ini adalah teori Nugroho dalam penelitian Mahfud (2015) yang membagi stakeholder menjadi lima sesuai dengan perannya dalam program pembangunan. Kelima peran tersebut antara lain policy creator, implementor, koordinator, fasilitator, dan akselerator.

\section{HASIL DAN DISKUSI/ANALISIS}

Kota Semarang merupakan Ibu Kota Provinsi Jawa Tengah dengan luas 373,8 $\mathrm{km}^{2}$. Kota Semarang terbagi menjadi 16 kecamatan dan 177 kelurahan. Jumlah penduduk Kota Semarang pada tahun 2019 adalah 1.814 .110 jiwa. $30,77 \%$ dari total penduduk Kota Semarang berada di usia 0-19 tahun.

Berdasarkan Peraturan

Daerah Kota Semarang Nomor 5 Tahun 2016 tentang Perlindungan Perempuan dan Anak dari Tindak Kekerasan, disebutkan bahwa pemerintah daerah melakukan upaya pemulihan kepada korban. Pemulihan ini termasuk menyiapkan pendampingan psikososial, lingkungan keluarga, dan sekolah. Dinas Pemberdayaan Perempuan dan Perlindungan Anak sebagai representasi pemerintah daerah kemudian membentuk lembaga penyelenggara perlindungan anak sesuai Peraturan Walikota Semarang Nomor 5 Tahun 2016. Dalam Peraturan tersebut, lembaga yang berwenang memberikan pelayanan perlindungan anak antara lain PPT SERUNI, PPT Kecamatan, Pos JPPA, dan Rumah Duta Revolusi Mental. Akan tetapi, pada awal tahun 2019 Rumah Duta Revolusi Mental mengalami pemindahan tanggungjawab di bawah Dinas Pendidikan.

\section{Peran Stakeholder}

\section{a. Policy Creator}

Policy creator adalah stakeholder yang berwenang dalam pengambilan keputusan dan pembuatan kebijakan perlindungan anak termasuk di dalamnya mencakup reintegrasi sosial bagi korban kekerasan. Stakeholder yang berperan sebagai policy creator adalah Dinas Pemberdayaan Perempuan dan Perlindungan Anak Kota Semarang. Regulasi tentang perlindungan anak merupakan hal yang mendasari seluruh kegiatan penyelenggaraan perlindungan anak di Kota Semarang. Berdasarkan Peraturan Daerah No. 5 Tahun 2016 pasal 8, DP3A sebagai representasi pemerintah daerah memiliki 
kewajiban untuk menetapkan, melaksanakan kebijakan, program dan kerjasama kegiatan dalam penyelenggaraan perlindungan anak. Hal ini sesuai dengan fungsi DP3A yang tertera dalam Peraturan Walikota Semarang Nomor 70 Tahun 2016 bahwa DP3A memiliki wewenang dalam perumusan kebijakan.

\section{b. Implementor}

Implementor merupakan stakeholder yang berperan sebegai pelaksana kebijakan perlindungan anak dari tindak kekerasan termasuk melaksanakan layanan reintegrasi sosial sesuai regulasi. Stakeholder yang berperan sebagai implementor terdiri dari DP3A, PPT SERUNI, PPT Kecamatan, dan Pos JPPA,

Sebagai Implementor, DP3A berperan untuk melakukan sosialisasi kepada masyarakat mengenai perlindungan anak. Hal ini penting dilakukan agar tidak terjadi diskriminasi ketika anak korban kekerasan kembali ke masyarakat. Akan tetapi, berdasarkan hasil wawancara dietahui bahwa sosialisasi yang dilakukan oleh DP3A masih kurang menjangkau masyarakat terutama di tingkat RT. Selain melakukan sosialisasi, DP3A juga berwenang untuk mengawasi dan mengevaluasi lembaga penyelenggaraan perlindungan anak di Kota Semarang.

PPT SERUNI memiliki lima layanan yang dapat diakses oleh korban kekerasan. Salah satunya adalah reintegrasi sosial. Layanan reintegrasi sosial merupakan layanan yang berfokus pada mengembalikan korban ke masyarakat. Korban kekerasan biasanya mengalami trauma dan rasa kurang percaya diri untuk kembali ke masyarakat. Dalam kasus kekerasan anak, yang paling dibutuhkan dalam reintegrasi adalah pemberian hak anak untuk bersekolah dan lingkungan keluarga alternatif. Reintegrasi sosial dapat berarti membantu korban mendapatkan tempat tinggal baru ataupun sekolah baru. Pada pelaksanaannya, PPT SERUNI bekerjasama dengan berbagai stakeholder seperti Dinas Sosial dan Dinas Pendidikan. Selain melaksanakan reintegrasi sosial, PPT SERUNI juga memiliki dua orang psikolog yang bertugas untuk konseling korban. Konseling bertujuan untuk mengetahui kondisi dan kebutuhan korban sehingga korban dapat menerima pelayanan sesuai dengan yang dibutuhkan.

Bertindak sebagai implementor, PPT Kecamatan melaksanakan pelayanan reintegrasi sosial di wilayahnya. Dalam menjalankan peran reintegrasi sosial, full timer PPT Kecamatan bekerjasama dengan berbagai pihak termasuk melakukan mediasi apabila dibutuhkan. Hal yang juga dilakukan oleh Pos JPPA, hanya saja cakupan Pos JPPA berada di tingkat kelurahan.

\section{c. Koordinator}

Stakeholder yang berperan untuk mengkoordinasikan stakeholder lain untuk pencapaian tujuan merupakan stakeholder yang berperan sebagai koordinator. Dalam upaya reintegrasi sosial anak korban kekerasan, yang berperan sebagai koordinator antara lain DP3A, PPT SERUNI, PPT Kecamatan, dan Pos JPPA.

DP3A berperan menjadi
koordinator
penyelenggaraan perlindungan anak yang termasuk di dalamnya PPT SERUNI, PPT Kecamatan dan Pos JPPA. Setiap kasus yang masuk wajib dilaporkan ke DP3A melalui laporan bulanan, aplikasi ASIKK PaK, dan rapat koordinasi tiap bulan. Melalui aplikasi ASIKK PaK, Kepala Bidang Perlindungan Perempuan dan Anak 
dapat memonitor kasus yang masuk sejak pengaduan hingga reintegrasi sosial. Sementara itu, Kepala Seksi Pencegahan dan Penanganan Kekerasan merupakan manajer kasus sehingga apabila terdapat kasus yang rumit maka wajib berkonsultasi terlebih dahulu dengan DP3A.

PPT SERUNI merupakan koordinator pelayanan perlindungan anak di tingkat kota. Dalam menjalankan perannya, PPT SERUNI bekerja sama dengan berbagi stakeholder yang telah tergabung dalam SK Keanggotaan PPT SERUNI termasuk di dalamnya Dinas Pendidikan, Dinas Sosial dan Dinas Kesehatan. PPT SERUNI juga mengadakan rapat koordinasi dengan seluruh anggota setiap enam bulan sekali.

Kota Semarang memiliki 16 PPT Kecamatan. PPT Kecamatan merupakan stakeholder yang berperan sebagai koordinator pelayanan di tingkat kecamatan. Dalam melaksanakan pelayanan reintegrasi sosial, PPT Kecamatan akan berkoordinasi dengan stakeholder terkait sesuai dengan kebutuhan korban. Apabila korban membutuhkan bantuan untuk mengakses pendidikan, maka PPT Kecamatan akan berkoordinasi dengan Dinas Pendidikan. Apabila korban membutuhkan pengasuhan keluarga alternatif, maka PPT Kecamatan akan berkoordinasi dengan Dinas Sosial. Selain itu, PPT Kecamatan juga menjalin kerjasama dengan lembaga penanganan kekerasan anak di tingkat kecamatan seperti Bhabinkamtibmas dan aparat pemerintah setempat seperti RT, RW, dan kelurahan. Kerjasama ini dilakukan dalam rangka melakukan mediasi dengan keluarga korban. Bhabinkamtibmas turut dilibatkan untuk memberikan perlindungan bagi full timer PPT Kecamatan dan korban.
Sementara itu, aparat pemerintah setempat seperti RT dan RW dilibatkan karena mereka yang mengetahui kondisi lingkungan di sekitar tempat tinggal korban.

Pos JPPA merupakan Pos Jaringan Perlindungan Perempuan dan Anak. Sebagai koordinator, Pos JPPA melaksanakan koordinasi dengan jaringan pelayanan perlindungan anak di tingkat kelurahan. Pos JPPA berkoordinasi dengan Bhabinkamtibmas, serta aparat pemerintah setempat.

\section{d. Fasilitator}

Fasilitator

merupakan stakeholder yang berperan untuk memenuhi kebutuhan korban. Dalam penelitian ini stakeholder yang berperan sebagai fasilitator bertindak untuk memfasilitasi kebutuhan korban dalam upaya kembali ke masyarakat sesuai dengan fungsi sosialnya. Stakeholder yang terlibat sebagai fasilitator antara lain DP3A, PPT SERUNI, PPT Kecamatan Pos JPPA, Dinas Kesehatan, Dinas Sosial, Dinas Pendidikan, Rumah Duta Revolusi Mental, rumah saktit, akademisi, dan Bhabinkamtibmas.

DP3A berperan untuk mendirikan lembaga perlindungan anak serta memberikan dukungan sarana prasarana. Gedung Sekretariat PPT SERUNI dibuat menggunakan anggaran DP3A. PPT SERUNI memfasilitasi kebutuhan korban dengan tetap melakukan pemantauan kondisi korban pasca pelayanan. Psikolog PPT SERUNI akan menanyakan kembali kondisi korban atau mengunjungi korban untuk memastikan kondisi korban setidaknya dua minggu setelah pelayanan selesai. Hal ini untuk memastikan korban dapat beradaptasi dengan baik setelah apa yang telah dialaminya. PPT SERUNI juga memberikan rujukan medis pada rumah sakit yang telah bekerja sama. 
selain itu, PPT SERUNI menyediakan rumah aman yang dapat diakses oleh korban apabila harus sembunyi untuk menyelamatkan diri dari ancaman pelaku. Korban bisa mengakses rumah aman apabila tidak mampu secara ekonomi dan tidak berdaya secara psikologi. Lokasi rumah aman hanya diketahui oleh sekretariat PPT SERUNI dan bagi korban yang ingin menggunakan rumah aman diwajibkan untuk menonaktifkan telepon seluler. Selama tinggal di rumah aman, korban akan didampingi oleh pengelola rumah aman dan segala kebutuhan korban dipenuhi oleh PPT SERUNI melalui anggaran DP3A. Selanjutnya peran PPT Kecamatan sebagai fasilitator antara lain memberikan rujukan medis dan melakukan pemantauan kondisi korban. Rujukan medis diberikan pada korban dan dapat diakses secara gratis pada rumah sakit yang telah bekerjasama dengan DP3A dalam penanganan kekerasan anak. Sementara pemantauan korban dilakukan setidaknya dua minggu setelah koban dikembalikan ke masyarakat. pemantauan ini bertujuan untuk mengetahui keadaan korban, apabila korban merasa membutuhkan konseling lebih lanjut dan sulit beradaptasi maka PPT Kecamatan akan memberikan rujukan pelayanan psikologis ke PPT SERUNI atau akademisi. Pos JPPA memiliki peran untuk melakukan pemantau korban dan memberikan rujukan medis bagi korban kekerasan. Korban yang melapor ke Pos JPPA dapat diarahkan untuk mendapat pelayanan medis di rumah sakit serta pemulihan psikososial di PPT SERUNI ataupun di akademisi/universitas yang telah bekerjasama. Sementara pemantauan kondisi korban tetap berjalan setidaknya dua minggu pasca penanganan.
Organsasi perangkat daerah selain DP3A juga berperan dalam reintegrasi sosial korban kekerasan. Dinas Kesehatan Kota Semarang berperan untuk memberikan Universal Health Coverage (UHC) pada korban agar dapat mengakses kesehatan secara gratis. Anggaran layanan kesehatan bagi korban juga berasan dari anggaran Dinas Kesehatan Kota Semarang. Sementara itu, Dinas Sosial berperan untuk membantu mencari keluarga alternatif bagi korban melalui pantipanti sosial. Selain itu, Dinas Sosial juga mendirikan Pusat Kesejahteraan Sosial Anak Integratif (PKSAI) untuk menjamin hak-hak anak dalam situasi rentan termasuk anak korban kekerasan. Dinas Pendidikan berperan untuk menjamin hak anak untuk mendapatkan pendidikan. Dinas Pendidikan mengeluarkan Peraturan Walikota Semarang dan Peraturan Kepala Dinas Pendidikan Semarang terkait sekolah ramah anak yang melarang anak korban kekerasan dikeluarkan dari sekolah. Kebijakan afirmasi yang diberkan oleh Dinas Pendidikan membuat korban kekerasan dapat bersekolah di sekolah negeri. Dinas Pendidikan melatih guru-guru di sekolah untuk mengenali dan mencegah kekerasan atau diskriminasi di lingkungan sekolah. Hal yang sama dilakukan oleh Rumah Duta Revolusi Mental. Sebagai bagian dari Dinas Pendidikan, Rumah Duta Revolusi Mental berperan untuk mencegah kekerasan di lingkungan sekolah. RDRM juga menyediakan psikolog yang dapat diakses apabila korban mengalami bullying di sekolah.

Stakeholder yang turut memfasilitasi kebutuhan korban kekerasan adalah rumah sakit. Rumah sakit yang telah bekerjasama dengan DP3A untuk memberikan pelayanan gratis antara lain Rumah 
Sakit Bhayangkara, Rumah Sakit Wongsonegoro, dan Rumah Sakit Tugurejo. Rumah sakit berperan untuk memberikan layanan medis bagi korban. Selain itu, apabila korban membutuhkan psikiater maka lembaga perlindungan anak dapat merujuk korban ke rumah sakit. Pelayanan psikologis juga dapat dberikan oleh akademisi/universitas yang telah bekerjasama yaitu CTR Unika Soegijapranata. Layanan konseling psikologis penting untuk mengembalikan kepercayaan diri korban agar tidak menyalahkan diri sendiri dan mengurangi trauma sehingga dapat kembali ke lingkungan.

Stakeholder yang terlibat dalam reintegrasi sosial selanjutnya adalah Bhayangkara Pembina Keamanan dan Ketertiban Masyarakat (Bhabinkamtibmas). Bhabinkamtibmas berperan untuk mendampingi full timer PPT Kecamatan saat akan melakukan mediasi sehingga tidak terjadi hal-hal yang tidak diinginkan. Bhabinkamtibmas juga dapat membantu menjaga tempat tinggal korban apabila khawatir dengan ancaman pelaku.

\section{e. Akselerator}

Semua pihak yang terlibat dalam kebijakan perlindungan anak di Kota Semarang merupakan akselerator reintegrasi sosial karena mempercepat pencapaian tujuan. Kegiatan yang dilakukan dalam rangka mempercepat reintegrasi sosial adalah dengan melaksanakan tugas sesuai dengan kewenangannya masing-masing. Apabila salah satu pihak tidak memberikan kontribusi yang maksimal maka penyelenggaraan perlindungan anak akan terhambat.

\section{Faktor Penghambat}

\section{a. Kultur Masyarakat}

Kultur masyarakat masih menjadi penghambat dalam melakukan reintegrasi sosial korban kekerasan. Anak korban kekerasan distigma, diskriminasi masih terjadi di institusi pendidikan, dipandang sebelah mata di masyarakat serta orangtua yang menganggap bahwa kekerasan anak termasuk ranah pribadi sehingga pemerintah tidak berhak ikut campur menjadi penghalang reintegrasi sosial korban Kota Semarang. Anak sebagai korban merasa takut untuk melapor karena kekerasan yang dialami dianggap aib yang akan mencemarkan nama baik keluarga. Kultur masyarakat menghambat reintegrasi sosial bagi anak korban kekerasan karena PPT Kecamatan sering mengalami penolakan dari keluarga apabila menangani kasus kekerasan anak karena dinilai terlalu mencampuri urusan rumah tangga.

\section{b. Anggaran yang terbatas}

Anggaran untuk melakukan reintegrasi sosial terbatas, terutama dalam penyediaan kebutuhan korban di rumah aman. Seorang anak korban kekerasan dapat berlindung di rumah aman selama dua minggu. Dalam kurun waktu tersebut, seluruh biaya hidup ditanggung oleh pemerintah kota Semarang. Akan tetapi dalam realitanya, pemulihan korban membutuhkan waktu lebih dari dua minggu agar dapat kembali ke masyarakat. seorang anak yang mengalami kekerasan di panti sosial cenderung tidak ingin kembali ke tempat tersebut. Hal sama juga terjadi apabila seorang anak mengalami kekerasan di sekolah. Sehingga proses pemulihan dapat berlangsung selama berbulan-bulan, sementara anggaran yang ada hanya terbatas untuk dua minggu. 


\section{c. Trauma psikologis dalam diri korban}

Dalam beberapa kasus, hambatan pelaksanaan reintegrasi sosial timbul dari dalam diri anak itu sendiri. Anak yang menjadi korban merasa kurang percaya diri, malu, dan merasa berbeda dari teman sebayanya. Hal ini membuat anak takut untuk kembali ke sekolah. Berdasarkan wawancara dengan Dinas Pendidikan Kota Semarang, sekalipun telah melakukan konseling oleh psikolog dan dipantau keadaannya oleh guru di sekolah masih terdapat anak yang enggan kembali ke sekolah karena trauma.

\section{d. Regulasi yang mengatur reintegrasi sosial masih lemah}

Pelaksanaan reintegrasi sosial di Kota Semarang didasarkan pada Peraturan Daerah Kota Semarang Nomor 5 Tahun 2016. Di dalam pasal 18 mengenai pemulihan hanya dijelaskan bahwa pemulihan salah satunya meliputi pemulangan korban, pemulihan fisik, pemulihan psikososial, serta melakukan penyiapan lingkungan keluarga dan sekolah. Regulasi ini tidak menjelaskan bagaimana reintegrasi sosial anak korban kekerasan dilaksanakan, siapa saja pihak yang terlibat, serta berapa lama waktu yang dibutuhkan hingga korban benar-benar siap kembali beradaptasi di masyarakat. Akibatnya proses reintegrasi sosial tidak optimal.

\section{KESIMPULAN}

Dari hasil penelitian dapat disimpulkan bahwa berdasarkan teori Nugroho, stakeholder yang terlibat dalam reintegrasi sosial kasus kekerasan pada anak di Kota Semarang terdiri dari policy creator, implementor, koordinator, fasilitator, dan akselerator. Yang bertindak sebagai policy creator adalah DP3A.
Implementor terdiri dari DP3A, PPT SERUNI, PPT Kecamatan, dan Pos JPPA. Stakeholder yang berperan sebagai koordinator antara lain DP3A, PPT SERUNI, PPT Kecamatan dan Pos JPPA. Fasilitator reintegrasi sosial terdiri dari DP3A, PPT SERUNI, PPT Kecamatan Pos JPPA, Dinas Kesehatan, Dinas Sosial, Dinas Pendidikan, Rumah Duta Revolusi Mental, rumah sakit, akademisi/universitas, dan Bhabinkamtibmas. Sementara yang bertindak sebagai akselerator adalah semua stakeholder yang terlibat.

Faktor

penghambat reintegrasi sosial kasus kekerasan pada anak antara lain kultur masyarakat yang menganggap kekerasan sebagai aib sehingga menghalangi proses mediasi dengan alasan urusan pribadi, anggaran reintegrasi sosial yang terbatas, trauma dalam diri korban yang menyebabkan korban enggan kembali bersekolah atau kembali ke panti sosial serta regulasi yang mengatur reintegrasi sosial masih lemah.

\begin{tabular}{lcr}
\multicolumn{2}{c}{ Rekomendasi } & yang \\
disampaikan & adalah & Dinas \\
Pemberdayaan & Perempuan & dan \\
Perlindungan & Anak & melakukan \\
sosialisasi & mengenai & layanan \\
perlindungan & anak & serta
\end{tabular} mengedukasi sekolah dan panti sosial tentang pencegahan kekerasan pentingnya pemulihan dan reintegrasi bagi korban kekerasan. Selain itu, untuk mengatasi anggaran yang terbatas untuk rumah aman, DP3A dapat menganggarkan kembali dengan jumlah yang lebih banyak dari sebelumnya serta bekerjasama dengan stakeholder lain untuk membiayai perlindungan dan reintegrasi anak korban kekerasan. Untuk mengatasi trauma psikologis pada korban dapat dilakukan dengan konseling secara berkala baik dengan 
psikolog PPT SERUNI atau RDRM. Apabila dirasa tidak ada kemajuan maka dapat dirujuk ke psikolog profesional di rumah sakit. Hambatan regulasi yang masih lemah dalam mengatur reintegrasi sosial dapat diatasi dengan mengesahkan regulasi baru yang menjelaskan secara detai mengenai reintegrasi sosial sesuai kebutuhan korban.

\section{REFERENSI}

Agustino, L. (2016). Dasar-Dasar Kebijakan Publik. Bandung: Alfabeta.

Hasyim, N. (2018). Menyoal Pemulihan Anak Korban Kekerasan di Indonesia. PALASTREN Jurnal Studi Gender, 9(2), 305-323.

Indiahono, D. (2009). Kebijakan Publik Berbasis Dynamic Policy Analysis. Yogyakarta: Gava Media.

Krisdyawati, A. R., \& Yuniningsih, T. (2019). Efektivitas Dinas Pemberdayaan Perempuan dan Perlindungan Anak (DPPPA) Kota Semarang dalam Penanganan kasus kekerasan terhadap Anak Di Kota Semarang. Journal of Public Policy and Management Review, 8(2), 239-264. Retrieved from http://repositorio.unan.edu.ni/2 986/1/5624.pdf

Kusumanegara, S. (2010). Model dan Aktor dalam Proses Kebijakan Publik. Yogyakarta: Gava Media.

Mahfud, M. (2015). Peran Dan Koordinasi Stakeholder Dalam Pengembangan Kawasan Minapolitan Di Kecamatan Nglegok, Kabupaten Blitar. Jurnal Administrasi Publik Mahasiswa Universitas Brawijaya, 3(12),
2070-2076.

Moleong, L. J. (2016). Metodologi Penelitian Kualitatif. Bandung: Remaja Rosdakarya.

Mustikasari, N. A., \& Rostyaningsih, D. (2019). Evaluasi Kebijakan Perlindungan Anak dari Tindak Kekerasan di Kota Semarang. Journal of Public Policy and Management Review, 9(1), 1-15.

Noviana, I. (2015). Kekerasan seksual terhadap anak: dampak dan penanganannya. Sosio Informa, 1(1).

Putri, D. F. (2018). Analisa Stakeholder dalam Implementasi Kebijakan Kenanggulangan Kemiskinan Di Kota Madiun (Universitas Airlangga). Retrieved from http://repository.unair.ac.id/74 877/3/JURNAL_Fis.P.36 18 Put s.pdf

Putrihatiwi, E. I. A. S. S. A. G. P. (2017). Tugas dan Fungsi Dinas Pemberdayaan Perempuan dan Perlindungan Anak di Kota Semarang dalam Memberikan Perlindungan Hukum Terhadap Perempuan dan Anak dari Tindak Kekerasan. Diponegoro Law Journal, 6, 1-15. Retrieved from Fakultas Hukum, Universitas Diponegoro

Sugiyono. (2017). Metode Peneliitian Kuantitatif, Kualitatif, dan R\&D. Bandung: Alfabeta.

Suwanto, A., \& Dwi, Y. B. (2017). Implementasi Pelaksanaan Program Perlindungan Anak di Kota Semarang (Studi pada Badan Pemberdayaan Perempuan, Perlindungan Anak dan Keluarga Berencana (BP3AKB) Kota Semarang. Journal of Politic and Government 
Studies, 6(2), 281-290.

Syafiie, I. K. (2006). Ilmu Administrasi Publik. Jakarta: Rineka Cipta.

Wati, M. S. (2016). Perlindungan Perempuan Dari Tindak Kekerasan Di Kota Semarang. Journal of Public Policy and Management Review, 8.

Winarno, B. (2014). Kebijakan Publik (Teori, Proses, dan Studi Kasus). Jakarta: Buku Seru.

Yuniningsih, T. (2018). Analisis Jaringan Aktor Dalam Implementasi Kebijakan Pengembangan Pariwisata Kota Semarang. Universitas Diponegoro.

\section{Sumber-Sumber Lain:}

Peraturan Daerah Kota Semarang No. 5 Tahun 2016 tentang Perlindungan Perempuan dan Anak dari Tindak Kekerasan.

Peraturan Walikota Semarang Nomor 5 Tahun 2018 tentang Lembaga Penyelenggara Perlindungan Perempuan dan Anak dari Tindak Kekerasan di Kota Semarang.

Peraturan Walikota Semarang Nomor 70 Tahun 2016 tentang Kedudukan, Susunan Organisasi, Tugas dan Fungsi,serta Tata Kerja Dinas Pemberdayaan Perempuan dan Perlindungan Anak Kota Semarang. 